\title{
PRODUÇÃO CIENTÍ́fICA A RESPEITO DO ENSINO DE CLIMATOLOGIA NOS SIMPÓSIOS BRASILEIROS DE CLIMATOLOGIA GEOGRÁFICA
}

\author{
STEINKE, Ercília Torres - erciliaunb@gmail.com \\ Geógrafa. Profa. Adjunta da Universidade de Brasília (UnB). Coordenadora do Laboratório \\ de Climatologia Geográfica (LCGea) do Depto. de Geografia da UnB.
}

STEINKE, Valdir Adilson - valdirs@unb.br

Geógrafo. Prof. Adjunto da Universidade de Brasília (UnB). Coordenador do Laboratório de Geotecnologias e Multimídias (Lagim) da UnB e pesquisador do Laboratório de Climatologia Geográfica (LCGea) do Depto. de Geografia da UnB.

VASCONCELOS, Vanessa Cristina - nessacvlopes@gmail.com

Geógrafa. Estagiária do Laboratório de Climatologia Geográfica (LCGea) do Depto. de Geografia da UnB.

\begin{abstract}
RESUMO: Atualmente, apesar de pesquisas acadêmicas mostrarem esforços contínuos, o ensino de Climatologia, em todos os níveis, carece de estudos que apresentem resultados que auxiliem os professores a transformar os fenômenos complexos do clima em aulas interessantes para os alunos e que se apropriem de outras capacidades cognitivas além da memorização. Foi esse contexto que motivou a elaboração dessa pesquisa com o objetivo de identificar a participação de trabalhos a respeito do ensino de Climatologia ao longo das nove edições do Simpósio Brasileiro de Climatologia Geográfica, bem como refletir sobre os entraves do desenvolvimento de maiores pesquisas sobre o tema por parte da comunidade de geógrafos que desenvolve estudos nessa área. Para tanto, utilizou-se o levantamento dos cadernos de resumos publicados nos eventos. Os resultados mostraram que ainda há uma lacuna a ser preenchida na área de ensino de Climatologia para que novas práticas pedagógicas sejam desenvolvidas e visem o sucesso da aprendizagem.
\end{abstract}

Palavras chave: ensino, Climatologia, simpósio

SCIENTIFIC PRODUCTION ABOUT CLIMATOLOGY TEACHING OF GEOGRAPHICAL CLIMATOLOGY BRAZILIAN SYMPOSIA

ABSTRACT: Nowadays, despite the continuous effort from academic research, Climatology teaching, at all levels, has demanded studies in order to help teachers to turn complex phenomena on climate into interesting lessons. In addition, to make students incorporate other cognitive abilities apart from memorizing. This context motivated the conduction of this research aiming at identifying the submission of papers on Climatology teaching to the Simpósio Brasileiro de Climatologia Geográfica (Brazilian Symposium on Geographical Climatology) as well as reflecting upon the constrains to the development of major studies on the topic by the community of geographers studying the subject. For this, it was analyzed the book of abstracts published in the events. The results showed that there is still a gap to be filled in the area of Climatology teaching for new pedagogical practices are developed and aimed at the success of learning.

Key words: teaching, Climatology, symposium 


\section{INTRODUÇÃO}

Este trabalho foi desenvolvido na mesma linha de pensamento de Fialho e Azevedo (2006) e Fialho (2010), em que os autores tiveram a preocupação de analisar as pesquisas em Climatologia Geográfica publicadas nos anais dos Simpósios Brasileiros de Climatologia Geográfica (SBCG's). Porém, difere-se dos mesmos por discutir, especificamente, sobre a produção da comunidade de geógrafos, em relação ao ensino de Climatologia sob a perspectiva da Geografia.

Durante muitos anos o ensino da Geografia como um todo esteve submetido às normas de um ensino tradicional que, em suas raízes positivistas, limitava-se a descrever, quantificar e classificar os fenômenos para a compreensão do mundo. Desde então, o ensino da Geografia Física, em especial o da Climatologia, carrega essa herança positivista. Entretanto, com o surgimento de um movimento que critica esta configuração, surgiram novas propostas de ensino buscando trazer a visão do real, as relações e interações complexas da sociedade-natureza dentro do espaço social. Contudo, o que se observa é que a abordagem tradicional ainda é utilizada, principalmente, no Ensino Fundamental (PAULA E STEINKE, 2009).

Compiani (2002), afirma que, no processo de ensino-aprendizagem os recursos didáticos constituem-se em instrumentos basilares para a construção do conhecimento, e para que ele seja pensado, repensado e assimilado. Entre eles, o livro didático ainda constitui a principal fonte de conhecimento para os alunos e professores e, dependendo da localidade, a única fonte de conhecimento. Ocorre que, para a compreensão de conteúdos relacionados à Climatologia é necessário que o professor lance mão de outras práticas, recursos visuais e muitas ilustrações, pois o nível de abstração exigido para a compreensão dos fenômenos é elevado. Além disso, o professor também pode mostrar aos alunos que a Climatologia está presente no seu dia-a-dia.

E é essa postura que a Climatologia Geográfica busca prover em sua face escolar. Inserida na Geografia Física faz uma ponte dos conhecimentos técnicos à aplicação da vida diária dos estudantes. Para isso, busca apresentar e inserir os alunos na dinâmica climática local, regional e global, contextualizando com os problemas que a sociedade enfrenta e as suas ligações.

A importância da Climatologia no Ensino Básico vai além de puro conhecimento abstrato e é fundamental na formação de um cidadão critico ativamente participante na sociedade, pois os conceitos tratados pela Climatologia dos estudantes são relevantes para explicação e a compreensão de fenômenos que atingem diretamente ou indiretamente as sociedades.

Felizmente, tem crescido no Brasil, o número de pesquisas que tem como foco principal o desenvolvimento de novas práticas pedagógicas que não mais visem somente à descrição e memorização dos conteúdos de Climatologia, mas sim, que utilizem situações cotidianas e fatos conhecidos para explicar e analisar os fenômenos atmosféricos inseridos na realidade dos estudantes para que eles adquiram capacidade de estabelecer as relações entre as sociedades e as questões climáticas. 
Destacam-se como exemplos de pesquisas com esse panorama, os trabalhos de Fialho (2007), no qual o autor se preocupou em buscar novas possibilidades de ensino, a partir da constatação da prática da reprodução uma Climatologia despreocupada com a reflexão e a formação do cidadão consciente dos problemas sociais e ambientais que o cercam. Mendonça e Fernandes de Oliveira (2008), por sua vez, mostraram que o emprego da filmografia como estratégia de ensino em Climatologia traz boas contribuições para dinamizar as atividades didáticas. Da mesma forma, Santos (2008) elaborou um dicionário ilustrado dos principais conceitos da Climatologia e um jogo pedagógico para se trabalhar cada mecanismo climático. Maia e Maia (2010) demonstraram que é possível, utilizando-se o conhecimento popular, realizar uma prática pedagógica escolar que promova a compreensão de fenômenos atmosféricos ultrapassando a barreira da Climatologia Tradicional. Alves et al. (2010) realizaram um trabalho mostrando que a utilização de letras de músicas também constitui um excelente recurso didático para as aulas de Climatologia.

Muitas dessas pesquisas são divulgadas pelo Simpósio Brasileiro de Climatologia Geográfica (SBCG) que teve suas origens no ano de 1985, quando um grupo de Geógrafos iniciou a realização dos Simpósios de Geografia Física Aplicada (SBGFA) para que a comunidade de pesquisadores brasileiros dedicados aos estudos da Geografia Física pudessem se encontrar e debater sobre as novas perspectivas nas discussões empíricas e teóricas da ciência. Nesses encontros abria-se a oportunidade para a comunidade de geógrafos interessados em Climatologia discutirem seu espaço dentro da Geografia.

Em 1992, teve início uma série de eventos científicos específicos de Climatologia no âmbito da Geografia, seguindo o modelo do evento específico de Geomorfologia, iniciado em 1990. Surge, assim, em Rio Claro a primeira edição do Simpósio Brasileiro de Climatologia Geográfica (SBCG). De acordo com Zavatini (2000), esse evento,

(...) ao mesmo tempo em que comprovou a existência de uma comunidade geográfica que pensa e pratica Climatologia, revelou também uma produção científica rica, variada, embora por vezes equivocada, mas que, sem sombra de dúvida, representa as atuais preocupações dos geógrafos climatólogos. (Zavattini, 2000, p.243).

Desde então, já foram realizadas dez edições do evento que, segundo Sant'Anna Neto (2010), apresentaram resultados produtivos na área e tem dado consistência à comunidade de geógrafos que estudam o tempo e o clima. Uma avaliação detalhada do perfil dos trabalhos publicados nas edições dos SBCG, até 2008, pode ser encontrada no trabalho de Fialho (2010).

Foi o contexto de preocupação com o ensino de conteúdos de Climatologia, no Ensino Básico, sob a perspectiva de análise geográfica, tal qual preconiza Sant'Anna Neto (2008), da constatação da dificuldade dos professores de trabalharem com o tema e da falta de interesse dos alunos pela disciplina escolar (Taveira e Steinke, 2014; Steinke e Carvalho, 2013) que motivou a elaboração dessa pesquisa. O objetivo principal dessa investigação foi analisar os trabalhos apresentados nas dez edições do Simpósio Brasileiro de Climatologia Geográfica (SBCG), relacionados com o ensino de Climatologia, e elaborar uma síntese das 
abordagens mais significativas que expressam o conjunto da produção do período, tendo em vista os princípios da Climatologia que incorpore a dimensão social à interpretação do clima na perspectiva da análise geográfica, a Geografia do Clima.

\section{A GEOGRAFIA DO CLIMA NA ESCOLA}

No Ensino Básico, a incumbência da Geografia Escolar é preparar o aluno para se localizar no mundo, compreender o local onde vive e as relações entre natureza e sociedade. Um dos grandes desafios da Geografia na escola é estimular, no aluno, a capacidade de desenvolver o raciocínio espacial. Para isso, o planejamento das aulas deve contemplar o trabalho com conteúdos que permitam ao estudante compreender a posição que ocupa no espaço e as interações da sociedade em que vive com a natureza. Dependendo do nível, o currículo deve priorizar as questões locais, relacionando-as com as de caráter global, ou seja, a articulação entre as escalas não pode deixar de estar presente.

Diversas práticas didáticas podem ser aplicadas para que os alunos aprendam a fazer a leitura do mundo. Na Geografia Física, o trabalho de campo já é estratégia adotada por muitos professores. Uma boa opção de transferir os conceitos para a prática é fazer com os alunos uma visita a uma estação meteorológica, após serem trabalhados assuntos como, a diferença entre fatores e elementos climáticos e a entre tempo e clima. As cartas do tempo elaboradas pelas instituições de previsão de tempo também são muito úteis. Todavia, diferentes formas de representação da dinâmica espacial também levam ao conhecimento de um local e dos fenômenos que ali ocorrem. Entre elas podem ser destacadas: as fotos, pinturas, filmes, poemas, romances e textos jornalísticos. Esses outros recursos podem ser trabalhados para enriquecer a compreensão da influência dos fenômenos atmosféricos e dos padrões climáticos na estruturação do território e no cotidiano da sociedade.

A falta de entendimento/conhecimento dos temas relacionados à Climatologia, por parte de professores e alunos é algo assustadoramente aparente (TAVEIRA E STEINKE, 2014), sendo esta questão objeto de pesquisa e discussão por alguns estudiosos do ensino de Geografia. Os argumentos que levam a essa constatação são, principalmente: a pequena carga horária da disciplina de Geografia, a falta de material, a má formação do professor, a pouca estrutura oferecida pelas escolas e os baixos salários pagos aos professores. Todos esses fatores contribuem para a pouca relevância dada a este tema nas escolas.

Segundo Straforini (2002), nos primeiros ciclos do Ensino Fundamental, por exemplo, as aulas de Geografia, assim como das outras disciplinas que não sejam o Português e Matemática, ocupam um papel secundário, muitas vezes irrelevante no cotidiano da escola. Isso decorre da falta de discussões teóricas, metodológicas e epistemológicas, bem da formação dos professores, que assumem as suas dificuldades perante a discussão teórica das referidas disciplinas. Diante dessa situação, o conteúdo de Climatologia geralmente é deixado em segundo plano pelos professores. 
Entretanto, o que mais chama atenção é o fato de os conteúdos de Climatologia, na escola e nos livros didáticos, ainda não incorporarem a verdadeira dimensão geográfica do clima. Sant'Anna Neto (2008) acredita que o clima deve ser trabalhado como:

(...) fenômeno geográfico substanciado pelas aplicações de seu conhecimento no entendimento do território, não apenas como elemento natural, determinado pelas leis físicas, mas, também, pelo significado de sua repercussão nas relações entre a sociedade e a natureza mediadas pela ação dos agentes sociais, que produzem espaços concretos nos mais variados níveis de segregação e vulnerabilidade. (SANT'ANNA NETO, 2008, p.52).

O que se observa é que, tanto os conteúdos dos livros didáticos, como a postura do professor com relação a esses conteúdos, como observaram Taveira e Steinke (2014), não privilegia a dimensão social na interpretação do clima na perspectiva da análise geográfica. Ainda são enfatizados, no ensino da Climatologia Escolar, os processos dinâmicos e estruturas espaciais do clima em detrimento do significado desses mesmos processos inseridos nas dimensões socioeconômica e socioambiental.

Brito e Ferreira (2012) concordam que, infelizmente a abordagem dos conteúdos de Climatologia no Ensino Básico ainda se mostra muito tradicional. Os professores tratam os elementos climáticos de forma estática e aplicam exemplos distantes da realidade dos alunos. Estão perdendo a oportunidade de mostrar para o seus alunos que a repercussão dos fenômenos atmosféricos na superfície terrestre se dá em um território, transformado e produzido pelo homem, de maneira desigual e apropriado segundo os interesses de agentes sociais. A Climatologia escolar ainda discute muito pouco as principais dimensões socioeconômicas e ambientais afetadas pelo clima tais como as que Sant'Anna Neto (2008) destaca:

(...) a qualidade de vida e o conforto ambiental, considerando a apropriação e fragmentação do espaço urbano; o grau de interferência na rentabilidade agrícola, incorporando os aspectos de políticas públicas do setor e das novas tecnologias, que tendem a minimizar (ou não) o papel dos elementos do clima como insumo no processo de produção; a influência dos tipos de tempo na morbidade epidemiológica e nos casos de enfermidades, condicionados aos aspectos culturais (enquanto hábitos e costumes), da segregação socioespacial e do planejamento da saúde pública; e o diálogo com as proposições oficiais do IPCC (International Panel on Climate Change) para além da dimensão estritamente científica, investigando o que há por trás do discurso catastrofista, que sugere uma governança internacional, através de uma "pseudo" emergência global. Desvendar os conteúdos que se travestem de tragédia, mas que podem configurar-se como farsa. Ou seja, problematizar este discurso, à luz da contribuição de uma Geografia do Clima (Sant'Anna Neto, 2008, p. 53).

Para que isso ocorra, a Climatologia Escolar deve incorporar um entendimento dos fenômenos atmosféricos que responda às indagações e necessidades 
exigidas pela sociedade, o que Sant'Anna Neto $(2001,2008)$ denomina, muito apropriadamente, de Geografia do Clima.

A proposta do autor é avançar sobre a análise geográfica do clima que tem sido praticada desde o advento do paradigma do ritmo climático. Segundo ele, a grande maioria das investigações tem se pautado nas análises episódicas (análise rítmica) para tentar explicar a gênese dos processos atmosféricos intervenientes no espaço antropizado. Contudo, esse tipo de análise não consegue desvendar os mecanismos de feedback e nem dá conta de incorporar, nas propostas de gestão/monitoramento dos fenômenos atmosféricos, projeções de cenários futuros, pois está sustentada no tripé ritmo climático - ação antrópica - impacto ambiental.

O autor considera que a concepção de ação antrópica adotada, demonstra uma visão naturalista da relação sociedade-natureza e minimiza outros aspectos, como os de ordem social, econômica e ideológica, do processo de interferência e apropriação da natureza, para ele:

(...) antropizar o território significa mascarar as reais intenções dos agentes do sistema econômico hegemônico neste processo de apropriação, desviando as atenções da questão primordial, apropriação-utilização-reprodução da natureza, para uma questão secundária: demonstrar os diferentes graus de intervenção dos agentes envolvidos - os homens - desconsiderando-se sua organização social estabelecida numa sociedade de classes. (SANT'ANNA NETO, 2001, p.55).

Já em relação ao impacto ambiental, o autor entende que o que se tem feito nada mais é do que buscado a compreensão das relações causa-efeito do papel do clima na superfície terrestre, do que introduzir uma concepção de clima enquanto recurso próprio do processo de reprodução do capital e de dominação, com valor de uso. É por isso que o autor questiona, sob a égide da valoração dos recursos naturais, se o clima e o tempo atmosférico também tem valor; se existem limites toleráveis de produção de calor e de poluição do ar e da água; e se alguém pagará os danos ambientais e sociais produzidos. Em função desses questionamentos, afirma:

Não há dúvida de que estamos num momento interessante para avaliar de maneira mais crítica e socialmente mais justa onde estamos querendo chegar com as metodologias convencionais e com o paradigma rítmico e sistêmico. O fundamental é que o problema não está tão relacionado ao aparato técnico mas sim nas leituras que se tem feito a partir deles. (SANT'ANNA NETO, 2001, p.56).

Dessa forma o autor insiste em que haja uma busca por uma compreensão dos fenômenos atmosféricos que responda às questões das sociedades e não mais simplesmente compreender e explicar os mecanismos da circulação atmosférica e dos sistemas produtores de tempo. Para isso deve haver uma releitura dos atuais modelos ou a elaboração de novos métodos e paradigmas que permitam alcançar uma nova visão dos problemas que estão sendo colocados e que ainda não foram suficientemente incorporados, na busca de uma Climatologia eminentemente humana e geográfica. 


\section{PROCEDIMENTOS METOdOLÓgICOS}

Para investigar a produção de trabalhos a respeito do ensino de Climatologia foi realizado, primeiramente, um levantamento de todos os trabalhos publicados nos Anais dos Simpósios Brasileiros de Climatologia Geográfica (SBCG), realizados entre os anos de 1992 (Rio Claro-SP); 1996 (Presidente PrudenteSP); 1998 (Salvador-BA); 2000 (Rio de Janeiro-RJ); 2002 (Curitiba-PR); 2004 (Aracajú-SE); 2006 (Rondonópolis-MT), 2008 (Alto do Caparaó-MG), 2010 (Fortaleza - CE) e 2012 (Manaus - AM) onde foram analisados 1.246 trabalhos (esses foram levantados dos índices dos anais/cadernos de resumos dos eventos e do volume especial da Revista Geonorte/2012). Logo em seguida, foram avaliados aqueles trabalhos que se encaixavam na categoria de ensino de Climatologia. Ressalta-se que, nessa classe, foram separados aqueles trabalhos considerados como contribuição efetiva para o ensino-aprendizagem de temas em Climatologia no Ensino Básico e superior.

Após o levantamento dos trabalhos, os mesmos foram sistematizados e classificados de acordo com dois elementos: $1^{\circ}$ ) suas regiões de origem (Norte, Nordeste, Sul, Sudeste e Centro-Oeste) e $2^{\circ}$ ) categorias listadas a seguir, chamadas aqui de temas centrais da Climatologia estudada pelos geógrafos. Essa proposta de classificação teve como base os eixos temáticos dos simpósios, embora se observe que os títulos dos eixos mudam de edição para edição. No caso dessa pesquisa, optou-se pelos seguintes temas: 1) clima urbano; 2) clima e agricultura; 3); clima e saúde; 4) ensino de Climatologia; 5) mudanças climáticas; 6) dinâmica atmosférica; 7) clima e recursos hídricos; 8) impactos ambientais; 9) estudos regionais e locais; 10) Análise estatística em Climatologia; 11 ) outros.

Após a classificação, foi realizada a espacialização das informações, via sistema de informação geográfica, do número de trabalhos de cada um dos 11 eixos definidos, por edição do evento e por Unidade da Federação gerando dez cartogramas de distribuição espacial dos dados.

Na última etapa da pesquisa, os trabalhos selecionados, de todas as edições dos SBCG, referentes ao ensino de Climatologia foram lidos e analisados a luz de suas colaborações e enfoques a respeito do tema. Uma vez realizada essa leitura, elaborou-se uma síntese das principais abordagens sobre ensino de Climatologia no grupo da produção científica entre 1992 e 2012.

\section{RESULTADOS E DISCUSSÃO}

Após 20 anos da realização da primeira edição do evento, o panorama da produção científica e acadêmica em Climatologia Geográfica se mostra muito próspero, uma vez que o número de trabalhos apresentados aumentou de modo expressivo, em média $13 \%$ ao ano.

A figura 1 apresenta a evolução do total de trabalhos nos SBCG's. Três períodos podem ser destacados: o compreendido entre 1992 a 2000, com crescimento acima de 30\% para cada evento; o período entre 2004 a 2006, com acréscimo 
de 35\% no número de trabalhos, e o período de 2008 a 2010, com um incremento superior a $50 \%$ no volume de trabalhos.

Note-se que, da edição de 2010 para a de 2012 houve uma queda no número global de trabalhos apresentados. Seria possível especular uma "inesperada" queda no volume de trabalhos submetidos ao evento de 2012, e buscar as nuances do decréscimo de $20 \%$ registrado. No entanto, acredita-se que o fato reside na excepcionalidade no quantitativo de contribuições registradas no Simpósio de Fortaleza, no ano de 2010. Obviamente que, de imediato, julga-se que o destino/sede do evento por si só já é um atrativo extra para a maior participação da comunidade científica, pois Fortaleza é um dos mais interessantes destinos turísticos do Brasil, contudo, neste momento, não se pode afirmar tal relação causa-efeito direta. Ainda seria possível especular, questões relativas à própria divulgação do evento, mas nos faltam os elementos técnicos necessários para elaborar qualquer quadro analítico das especificidades que fizeram do evento de 2010 ser, no momento atual, o ponto "fora da curva".

Observa-se que, excluindo-se da análise a excepcionalidade, no período entre 2008 e 2012, houve um crescimento de $24 \%$ no número de trabalhos. Isso significa, portanto, que ainda há um ritmo crescente na quantidade de contribuições, tornando-se prematura qualquer análise que indique quedas. Mais profícuo é aguardar os eventos vindouros para qualquer análise mais pormenorizada em termos quantitativos de trabalhos apresentados nos Simpósios.

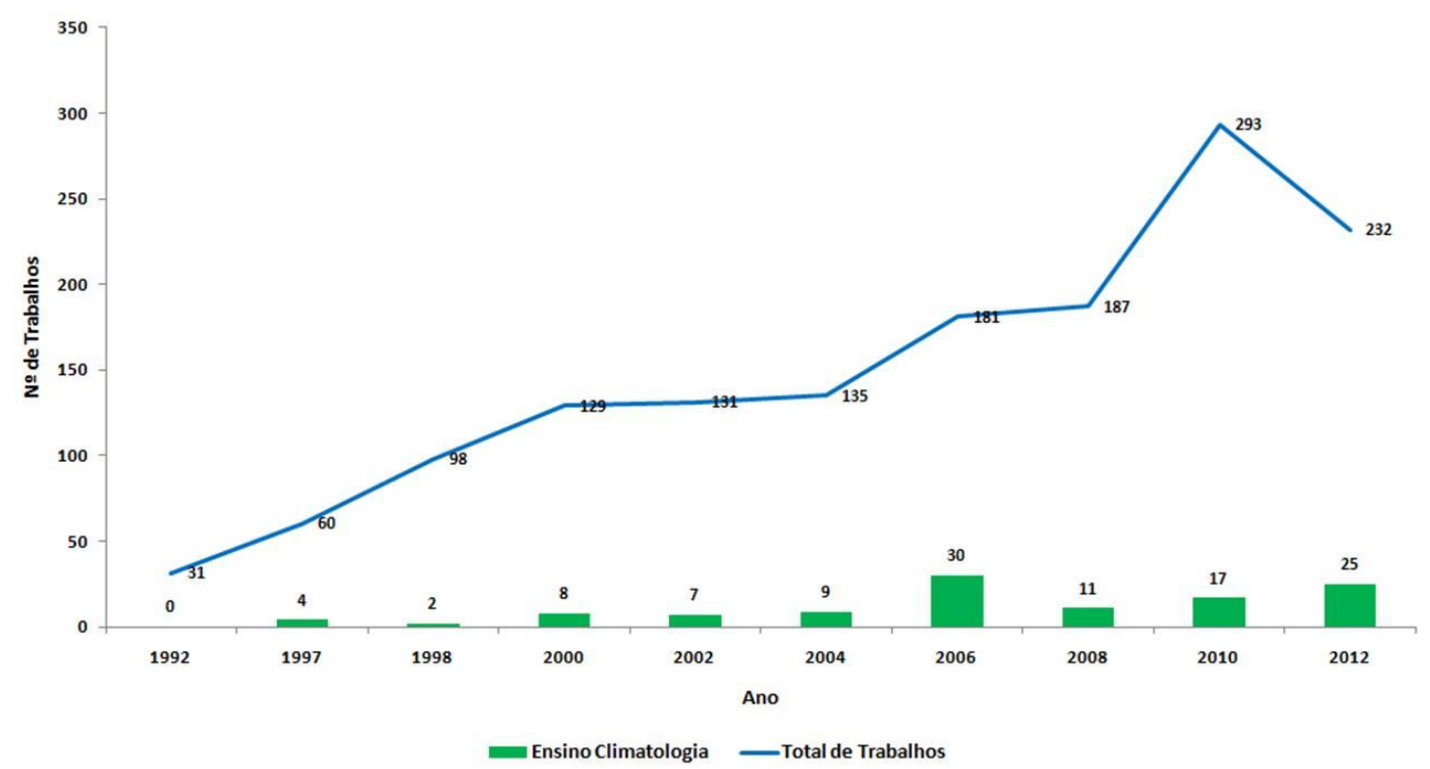

Figura 1 - Evolução do número total de trabalhos e daqueles relacionados ao ensino de Climatologia apresentados nos SBCG's, período 1992 - 2012.

Fonte: Anais dos SBCG's de 1992, 1996, 1998, 2000, 2002, 2004, 2006, 2008, 2010 e 1012.

Organizado por Valdir Adilson Steinke e Vanessa Cristina Vasconcelos. 
Fialho (2010), ao comentar sobre o acréscimo no número de publicações ao longo do tempo, afirma que o mesmo pode ter sido advindo da consolidação do evento junto às instituições de ensino universitário, assim como, do aumento da participação de grupos de pesquisa que se concretizaram por meio da criação de novos laboratórios de pesquisa em Climatologia.

As informações de todas as edições do evento foram sistematizadas na mesma perspectiva espacial, de modo que a dinâmica temporal pudesse se fazer representar em função das instituições de ensino e das respectivas regiões. Porém, nesse texto, por limitação de espaço, são apresentados somente os cartogramas referentes à primeira (1992) e à última edição (2012). Optou-se por essa escolha, uma vez que, dos inúmeros cartogramas gerados, esses podem ser aqueles que refletem algumas interessantes conclusões da pesquisa.

Avaliou-se a distribuição espacial da origem das pesquisas publicadas em cada edição do evento, uma vez que tal distribuição pode retratar, com certa fidelidade, a inserção regional de novos grupos de pesquisa em Climatologia Geográfica. Observa-se, na figura 2, referente ao evento realizado em 1992, a nítida a centralidade da região sudeste e, de modo especial do Estado de São Paulo, na origem dos trabalhos apresentados. Infere-se que isso seja reflexo contundente do maior volume de pesquisadores e projetos desenvolvidos nesta temática, à época, que foram provenientes da região onde ocorreu o evento. No entanto, chama atenção a participação de cinco trabalhos oriundos do estado do Pará.

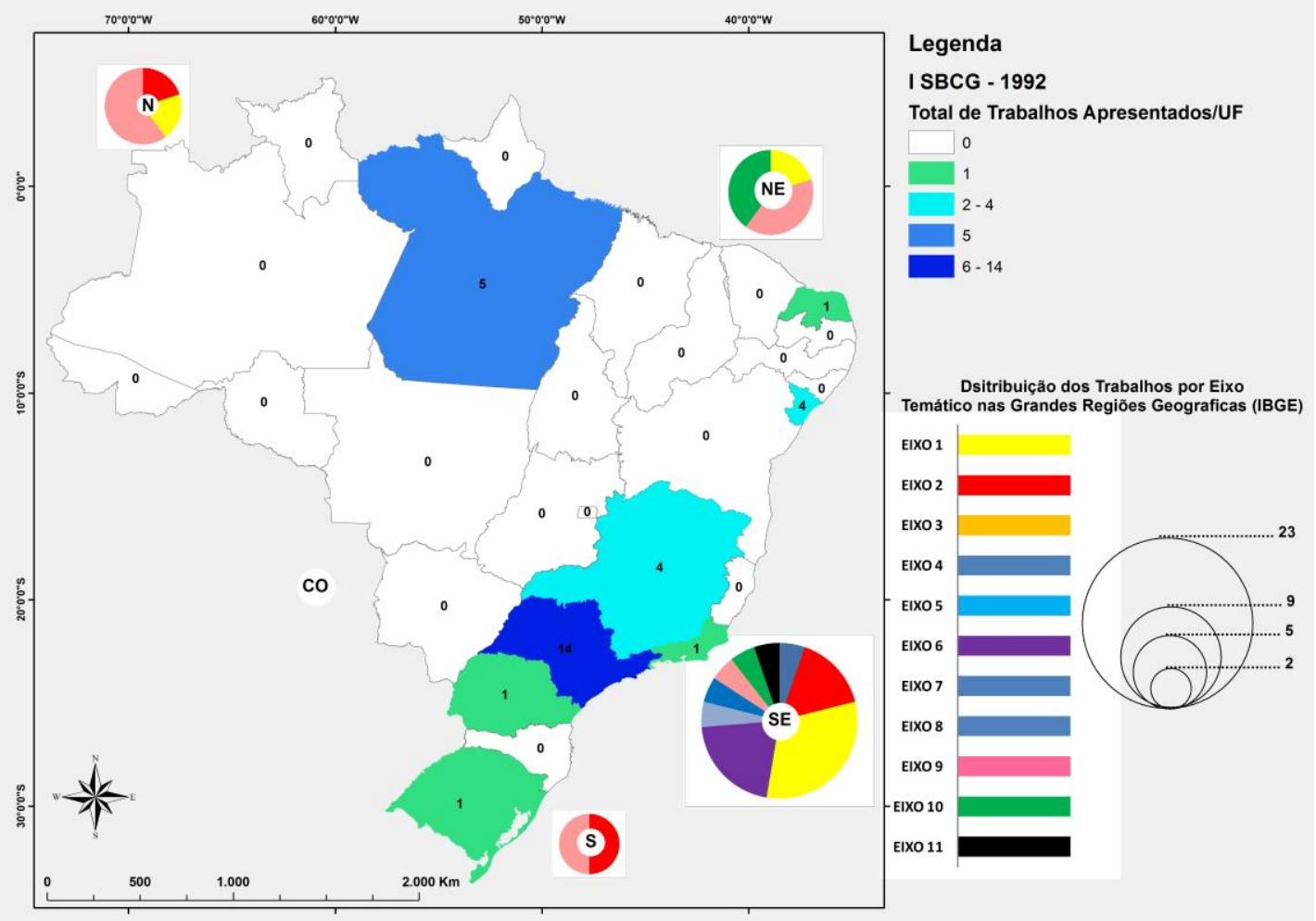

Figura 2 - Distribuição espacial dos trabalhos apresentados no SBCG em 1992.

Fonte: Anais dos SBCG de 1992.

Organizado por Valdir Adilson Steinke e Vanessa Cristina Vasconcelos. 
A figura 3, que representa a distribuição espacial dos trabalhos apresentados na última edição do evento, em 2012, mostra que a concentração de trabalhados oriundos da Região Sudeste, em todos os temas, continua sendo evidente, seguida da Região Sul. Nota-se, nessa edição a presença marcante de trabalhos dos estados de Minas Gerais e Ceará, com 44 e 31 contribuições, respectivamente. Observou-se que a participação desses dois estados vem crescendo paulatinamente desde 1992, juntamente com os demais. Isso demostra que outras realidades climáticas brasileiras estão sendo estudadas e, seus resultados divulgados para a comunidade científica. Em que pese, ainda de modo mais significativo, a concentração de pesquisas na região sudeste-sul, é evidente a existência de uma regularidade crescente, mesmo que em ritmo lento, nas demais regiões do Brasil. Esse fato demonstra o resultado da instalação de novos centros de pesquisa fora dos eixos mais tradicionais. 0 Nordeste e o Centro-Oeste, com a participação comparativamente elevada do estado de Goiás, merecem atenção neste sentido.

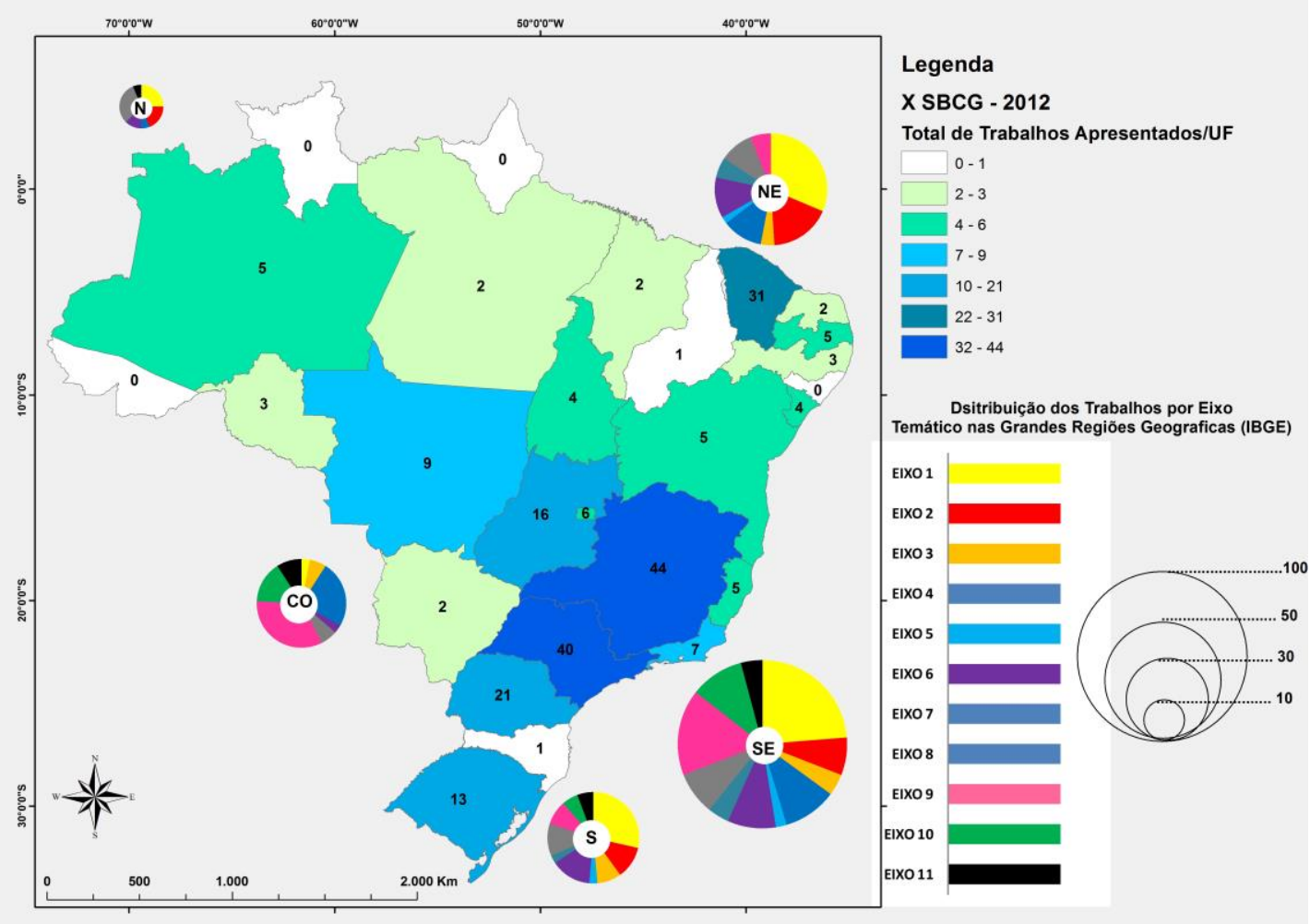

Figura 3 - Distribuição espacial dos trabalhos apresentados no SBCG em 2012. Fonte: Anais dos SBCG de 2012.

Organizado por Valdir Adilson Steinke e Vanessa Cristina Vasconcelos.

As informações a respeito do número de trabalhos publicados por tema e por edição dos SBCG's estão mostradas na tabela 1. Os primeiros eventos contaram com pequena participação de trabalhos, em todos os temas, de forma geral. A partir de 1998, a participação de estudos referentes às mudanças climáticas, 


\section{ISSN: 1980-055x (Impressa) 2237-8642 (Eletrônica)}

impacto ambiental e clima e saúde cresceu de forma significativa, sobretudo, em função da importância que se tem atribuído aos impactos provocados por mudanças climáticas e as suas implicações no ambiente, nos recursos hídricos, nas áreas urbanas, na saúde da população, e nas atividades agrícolas.

Apesar dessa constatação, observa-se que o número de trabalhos envolvendo o tema clima e agricultura, embora tenha apresentado um crescimento desde a primeira edição do SBCG, não apresentou significativa elevação. É possível que esse tema não seja muito valorizado, o que corrobora com as conclusões de Fialho (2010), em que uma avaliação criteriosa da contribuição dos geógrafos para a pesquisa em Climatologia Geográfica é realizada por esse autor.

Conforme a tabela 1 observa-se que o tema central que mais foi desenvolvido ao longo das dez edições do SBCG's é o que trata do clima urbano com suas vertentes de estudos sobre ilha de calor, campo térmico, poluição e impactos hidrometeóricos nas cidades. Este fato, segundo Fialho (2010), pode estar relacionado, principalmente, ao aumento dos experimentos de campo térmico que possibilitaram as medições dentro da cidade.

\begin{tabular}{|c|c|c|c|c|c|c|c|c|c|c|c|}
\hline $\begin{array}{l}\text { Temas / Número } \\
\text { de trabalhos } \\
\text { publicados nos } \\
\text { Anais } \\
\end{array}$ & 1992 & 1996 & 1998 & 2000 & 2002 & 2004 & 2006 & 2008 & 2010 & 2012 & total \\
\hline 1. Clima urbano & 1 & 11 & 25 & 23 & 17 & 16 & 37 & 37 & 83 & 56 & 306 \\
\hline $\begin{array}{l}\text { 2. Clima e } \\
\text { agricultura }\end{array}$ & 5 & 7 & 4 & 9 & 11 & 20 & 16 & 15 & 15 & 23 & 125 \\
\hline 3. Clima e saúde & 0 & 2 & 2 & 7 & 12 & 9 & 12 & 18 & 15 & 11 & 88 \\
\hline $\begin{array}{l}\text { 4. Ensino de } \\
\text { Climatologia }\end{array}$ & 0 & 4 & 2 & 8 & 7 & 9 & 30 & 11 & 17 & 22 & 110 \\
\hline $\begin{array}{l}\text { 5. Mudanças } \\
\text { climáticas; }\end{array}$ & 7 & 5 & 4 & 7 & 26 & 8 & 24 & 21 & 2 & 4 & 108 \\
\hline $\begin{array}{l}\text { 6. Dinâmica } \\
\text { atmosférica }\end{array}$ & 5 & 4 & 15 & 16 & 8 & 13 & 14 & 9 & 29 & 22 & 135 \\
\hline $\begin{array}{l}\text { 7. Clima e } \\
\text { recursos hídricos }\end{array}$ & 1 & 3 & 4 & 11 & 7 & 21 & 17 & 21 & 39 & 8 & 132 \\
\hline $\begin{array}{l}\text { 8. Impactos } \\
\text { ambientais; }\end{array}$ & 1 & 6 & 9 & 15 & 20 & 8 & 18 & 21 & 20 & 24 & 142 \\
\hline $\begin{array}{l}\text { 9. Estudos } \\
\text { regionais e } \\
\text { locais; }\end{array}$ & 7 & 9 & 19 & 13 & 4 & 14 & 5 & 16 & 45 & 34 & 166 \\
\hline $\begin{array}{l}\text { 10. Análise } \\
\text { estatística em } \\
\text { Climatologia: }\end{array}$ & 3 & 4 & 3 & 4 & 1 & 6 & 0 & 2 & 10 & 17 & 50 \\
\hline 11. Outros & 1 & 5 & 11 & 16 & 18 & 11 & 8 & 16 & 18 & 9 & 113 \\
\hline
\end{tabular}

Tabela 1 - Numero de trabalhos publicados por tema e por edição do Simpósio Brasileiro de Climatologia Geográfica - SBCG.

Fonte: Anais dos SBCG's de 1992, 1996, 1998, 2000, 2002, 2004, 2006, 2008, 2010 e 2012.

Organizado por Valdir Adilson Steinke e Vanessa Cristina Vasconcelos.

Entretanto, é possível que isso também esteja atrelado ao fato de as principais referências básicas dos geógrafos, na perspectiva da Climatologia Geográfica, serem aquelas relacionadas ao legado que o professor Carlos Augusto de Figueiredo Monteiro nos deixou a respeito do estudo do clima urbano. 
Provavelmente, a concepção geográfica do clima esteja sendo tratada, de forma equivocada, como sinônimo de estudar o clima das cidades. Quando, na verdade, é muito mais que isso.

Sant'Anna Neto (2010) acredita ser um desafio para a comunidade de geógrafos estudiosos da Climatologia, construir um conhecimento que fortaleça a unidade da ciência geográfica. Isso porque o autor questiona o fato de que, apesar das variações temáticas verificadas desde a primeira edição do SBCG, mudanças do ponto de vista teórico não foram identificadas, já que tanto a técnica de análise rítmica quanto o Sistema Clima Urbano continuam sendo as referências básicas para os estudos da Climatologia Geográfica.

Por outro lado, o tema que menos foi tratado, em todas as edições do SBCG, diz respeito à análise estatística em Climatologia, apesar de na segunda edição ter sido definido um eixo temático específico para o assunto. Observa-se, também, que na edição de 2012 houve um aumento significativo (80\%) nos trabalhos com esse tema em relação a 2010. Esse aumento justifica-se, pois muitos dos trabalhos apresentados no eixo "a Climatologia e as novas tecnologias" abordavam técnicas estatísticas como metodologia da pesquisa.

Esse fato faz pensar que o geógrafo estudioso do clima ainda privilegia demasiadamente a investigação dos processos dinâmicos e das estruturas espaciais e temporais do clima, em detrimento da importância que as técnicas estatísticas e de quantificação, atreladas às novas tecnologias, desempenham no aperfeiçoamento do instrumental do geógrafo para estudar o significado do clima inserido na dimensão social. Este fato pode estar relacionado com a falta de costume dos geógrafos com a quantificação, como afirma Sant'Anna Neto (2001):

\begin{abstract}
"Acontece que a linguagem matemática e a compreensão dos fenômenos físicos ainda nos são caros e, invariavelmente, temos enormes dificuldades em penetrar nos meandros daquelas ciências. Em parte pela nossa formação humanística; mas também é verdade que desconfiamos um pouco do arsenal extremamente técnico e quantitativo sob o qual repousam seus procedimentos de análise." Sant'Anna Neto (2001:57).
\end{abstract}

Possivelmente é chegada a hora de os geógrafos se debruçarem um pouco mais sobre o arcabouço matemático que nos está disponível, para que se possa incrementar os estudos e, com isso, avançar na produção do conhecimento em Climatologia verdadeiramente geográfica, extrapolando o binômio: identificação dos sistemas geradores dos eventos versus fato geográfico, tentando alcançar, assim, o que Sant'Anna Neto (2001) chama de Geografia do Clima, como já citado, aquela em que se busca uma nova concepção de clima com relação à produção do espaço geográfico, isto é, considerar o clima como um produto social. 


\section{SÍNTESE DAS ABORDAGENS MAIS SIGNIFICATIVAS SOBRE O ENSINO DE CLIMATOLOGIA NO CONJUNTO DA PRODUÇÃO CIENTÍFICA ENTRE 1992 E 2012, NOS SBCG'S.}

Com relação aos trabalhos incluídos na categoria "ensino de Climatologia", objeto principal desse estudo, verificou-se que o tema também não foi dos mais valorizados pelos que contribuíram com seus estudos nas dez edições do SBCG's. Em 1992, não foi publicado nenhum trabalhado com essa temática e nem mesmo foi definido um eixo temático específico para tal.

Já na segunda edição (1996) o tema foi abordado, porém, os trabalhos a respeito do ensino foram disponibilizados juntamente com aqueles de outra natureza, uma vez que o título do eixo temático, indicado para a publicação dos trabalhos de ensino, foi chamado de "Ensino de Climatologia/Outros". Nessa edição, dos quatro trabalhos apresentados, dois tratavam de práticas didáticas (RIBEIRO, et al., 1996 (a) e RIBEIRO et al., 1996 (b)) e os outros versavam sobre a abordagem do conteúdo de Climatologia nos livros didáticos (FERREIRA e DANIEL, 1996; VILLA e TAVARES, 1996).

$\mathrm{Na}$ terceira edição (1998) houve espaço específico para a divulgação dos trabalhos referentes ao ensino, contudo, somente dois trabalhos foram inscritos. O título do eixo temático foi chamado de "Metodologia, Técnica, Pesquisa e Ensino de Climatologia". Um dos trabalhos relatava a experiência com uma prática didática (FREIRE, 1998), e o outro discutia a abordagem dos conceitos climatológicos no livro didático de Geografia (CRISCUOLO et al., 1998). A despeito do número reduzido de pesquisas apresentadas, considera-se que nessa edição foi atribuída importância para o tema, já que houve um minicurso sobre Climatologia no Ensino Fundamental, ministrado pelo professor Dr. José Bueno Conti e, uma mesa redonda, intitulada "Climatologia e ensino: da escola básica à pós-graduação", cuja palestrante foi a professora Dra. Magda Adelaide Lombardo.

Na quarta (2000), quinta (2002) e sexta (2004) edições, entende-se que o tema ensino de Climatologia voltou a perder espaço entre os demais eixos estruturantes, uma vez que não houve definição de um eixo específico para o tema e os trabalhos publicados foram encaixados em eixos de outros assuntos correlacionados. Na quarta edição (2000), por exemplo, os oito trabalhos sobre ensino estavam inseridos no eixo denominado de "Climatologia Geográfica e a Educação Ambiental: Aplicações e Desafios". Dessas oito investigações apresentadas, cinco delas relatavam os resultados de práticas didáticas com estações meteorológicas; uma delas abordava os erros conceituais encontrados nos livros didáticos de Geografia, e duas versavam sobre a educação ambiental sob o viés do clima.

Destaca-se que, desde a primeira edição do evento, esta foi a primeira vez que uma pesquisa trouxe à tona a questão do ensino da Climatologia como fato geográfico (TUNES e SANTOS, 2000). Os autores ressaltaram que Climatologia tem se desenvolvido amplamente no meio acadêmico, apresentando novas abordagens e métodos de estudo, mas, que esse avanço tem ficado restrito à academia, não se refletindo na escola. Segundo os autores, isso ocorre, em parte, devido à confusão disciplinar em que esse tema é tratado no currículo do 
Ensino Básico, onde parte do conteúdo é atribuída à disciplina de Ciências, e outra à disciplina de Geografia. O problema que surge é o rompimento do entendimento de um processo que, pelo seu dinamismo e complexidade, não pode ser compreendido dessa forma multifacetada. Além disso, Tunes e Santos (2000) também consideram:

(...) necessário aqui retomar alguns conceitos chaves da Climatologia Geográfica, que possam subsidiar o professor de Geografia na sala de aula, já que muitas vezes os livros didáticos não abordam esses conteúdos, ou o fazem com pouca preocupação metodológica. (TUNES e SANTOS, 2000, p.2).

Apesar do intuito dos autores em chamar atenção para o ensino da Climatologia sob o âmbito da Geografia, quando afirmam que:

Na verdade, queríamos que os alunos, ao se depararem com uma questão geográfica, seja ela qual for, pudessem relacionar esse conteúdo com o seu cotidiano, e assim aproximar-se mais do entendimento do próprio objeto da geografia: o espaço geográfico. Assim, quando propusemo-nos a trabalhar com a temática de climatologia, buscamos uma forma de não limitar-se a caracterização dos climas brasileiros, nem a particularização do clima como um fenômeno separado da dinâmica da natureza.

Pretendíamos que o aluno ao pensar no clima, relaciona-se os demais fenômenos naturais, relacionando dessa forma um com o outro, pensando sempre em suas próprias experiências. (TUNES e SANTOS, 2000:6).

os mesmos não indicaram quais são os conceitos chaves da Climatologia Geográfica que deveriam ser trabalhados, e nem desenvolveram a temática sob a luz do significado dos processos climáticos inseridos na dimensão social, ficando sua investigação no campo da Climatologia Geográfica entendida como abordagem interdisciplinar na compreensão da relação homem-naturezasociedade no ensino de Geografia. Na pesquisa de Tunes e Santos (2000) não foi possível identificar a intenção de ensinar sob a verdadeira análise geográfica do clima que, segundo Sant'Anna Neto (2001), deve atender as exigências expectativas da sociedade, explicando como, e em quais situações, o território foi produzido e como afetam de forma diferenciada as sociedades.

A despeito da falta de um eixo temático exclusivo para o ensino de Climatologia, os organizadores da quarta edição do SBCG não negligenciaram totalmente o assunto, uma vez que três mesas redondas foram organizadas para essa discussão, com as seguintes palestras: "Climatologia Geográfica e Educação Ambiental", "A Climatologia Geográfica no Brasil: do que se tem Produzido ao que se tem Ensinado" e "Climatologia Geográfica: Velhas e Novas Formas do Ensino Interdisciplinar tendo como Recurso o Estudo do Meio e Informática", proferidas, respectivamente, pelos professores Doutores José Bueno Conti, João Lima Sant'Anna Neto e Magda Adelaide Lombardo.

Vale lembrar que o IV SBCG foi palco da criação da Associação Brasileira de Climatologia (ABCLIMA) com o objetivo de, segundo Fialho (2010), 
(...) dinamizar a comunidade de pesquisadores, potencializando trabalhos conjuntos, não deixando que apenas os encontros nacionais pudessem ser o único vetor catalisador de contatos e desenvolvimento de eventos de escala local e regional e da elaboração de um veículo de comunicação, agregação e divulgação de trabalhos FIALHO (2010, p. 195).

A quinta edição do SBCG (2002) também não contou com um eixo temático de ensino de Climatologia. Os sete trabalhos que versavam sobre o tema encontram-se dispersos nos eixos "Outros" e "Climatologia aplicada: saúde pública, turismo e educação ambiental". Dessas sete pesquisas, uma buscou verificar como os conceitos de clima e tempo são abordados nos livros didáticos de Geografia das escolas estaduais de Ensino Fundamental (MISSIO et al., 2002). Cinco trabalhos trouxeram relatos de práticas de ensino no Ensino Básico com a utilização de estação meteorológica, imagens de satélite e multimídia e apenas um apresentou os resultados de uma experiência de trabalho desenvolvida na disciplina de Climatologia de um curso de graduação onde os alunos foram envolvidos em atividades práticas. Verifica-se que, tal qual a edição anterior, o ensino de Climatologia foi enquadrado juntamente com a educação ambiental. Além disso, nenhuma das pesquisas abordou a questão da Climatologia Geográfica, mas sim, tratou o clima como fenômeno natural.

Em 2004 realizou-se a sexta edição do SBCG, em Sergipe. Foram identificados nove trabalhos sobre ensino de Climatologia que foram apresentados sob o eixo intitulado "Teorias e Métodos em Climatologia Geográfica". Entre esses nove, dois analisaram os conteúdos de Climatologia nos livros didáticos, seis relataram investigações diretas sobre o aprendizado de temas em Climatologia com alunos nas escolas e, apenas um, levantou a possibilidade de trabalhar a Climatologia Geográfica com os professores do Ensino Básico.

Destaca-se o trabalho de Machado et al. (2004) sobre a percepção dos alunos de um curso de graduação em Licenciatura em Geografia frente ao conteúdo de Climatologia por meio da observação sensível dos elementos do clima e a coleta da chuva. Da mesma forma ressalta-se o trabalho que Sousa et al. (2004) desenvolveram com o objetivo de auxiliar o entendimento e melhorar a compreensão dos alunos - professores, também de um curso de graduação, sobre os elementos e fatores climáticos por meio de uma a oficina, denominada de Construção e Equipamentos Meteorológicos.

Já nas sétima (2006), oitava (2008) e nona (2010) edições, o tema voltou a receber um eixo temático exclusivo para o mesmo, porém, com títulos diferenciados, respectivamente, "Clima e Ensino - teoria e prática", "Teoria e Ensino de Climatologia" e "Clima e ensino".

Observa-se que na edição de 2006 o número de trabalhos sobre ensino teve um aumento expressivo, quase quatro vezes em relação à edição anterior do evento, porém, de forma geral, as abordagens continuaram as mesas das outras edições, ou seja, relatos de experiências bem sucedidas de práticas que contemplassem outras formas de ensinar e análise dos conteúdos de Climatologia em livros didáticos. Apesar disso, merecem destaque algumas 
pesquisas, das quais se cita aqui três: a de Zavattini et al. (2006) cujo objetivo foi verificar como o assunto clima era abordado pela Geografia Italiana, seja no ensino básico ou na universidade, confrontando com o modo da Geografia Brasileira; e a de Lima (2006) e Pimentel e Costa (2006) sobre a sobre o ensino de Climatologia e Meteorologia, respectivamente, no curso de graduação em Geografia.

Em 2008 e 2010 observa-se que o quantitativo de trabalhos voltou a diminuir, embora tenha havida a definição de eixos específicos para o tema. Vale ressaltar que não foi identificada nenhuma pesquisa que tratasse do ensino de Climatologia com o viés da Geografia preconizada por Sant'Anna Neto (2001, 2008). Em 2008 destaca-se o trabalho de Mendonça et al. (2008) a respeito da utilização de filmes nas aulas de Climatologia em um curso de graduação. De acordo com os autores, a proposta para o emprego da tecnologia cinematográfica em contexto de sala de aula contribui para um maior dinamismo do ensino de temas dessa natureza. Além disso, acreditam que quando um filme é utilizado como recurso didático no processo ensino-aprendizagem:

ele abre interessante oportunidade para o trabalho interdisciplinar, pois a linguagem cinematográfica traz, dentre outros, situações do cotidiano em que se inter-relacionam elementos dos mais variados conteúdos disciplinares numa dinâmica real, que emana da imprevisibilidade dos acontecimentos do dia-a-dia dos personagens, seus discursos, intenções, ações e experiências. (Mendonça et al., 2008, p. 18)

Outra interessante pesquisa foi a de Santos (2008), na qual a autora aponta novas formas de se trabalhar o conteúdo programático de Climatologia no Ensino Básico para uma mais fácil apreensão do conteúdo. Apresenta um projeto no qual o aluno, na escola, pode aprender o conteúdo climático a partir de jogos educativos elaborados em parceria com os alunos do curso de graduação em Geografia. Os resultados mostraram que a atividade despertou nos alunos uma nova prática pedagógica associando ao ensino a necessidade de atividades práticas para a compreensão dos conteúdos.

$\mathrm{Na}$ nona edição (2010) houve um aumento de contribuições, sobretudo a respeito da utilização de outros recursos didáticos além do livro. Maia e Maia (2010), apresentaram uma prática utilizando os ditos populares. Alves et al. (2010) mostraram que a utilização de letras de músicas pode constituir um ótimo recurso didático para as aulas de Climatologia. Já Costa et al. (2010) e Braga (2010) apresentaram propostas de ensino com a utilização das tecnologias de Informação e Comunicação - TIC's e com o uso de um sítio da internet, respectivamente. Ambas as investigações concluíram que os recursos podem, com a devida mediação do professor, auxiliar no processo de ensinoaprendizagem dos conteúdos referentes ao clima.

A última edição (2012) contou com 25 trabalhos sobre o ensino de clima. Contudo, os enfoques não se diferenciaram muito das outras edições. O ponto central das pesquisas, de forma geral, girou em torno das seguintes abordagens: importância dos trabalhos práticos, dificuldades que os professores e os alunos, no Ensino Básico, possuem em ensinar e aprender, respectivamente, os 
conteúdos de Climatologia, problemas com conteúdos dos livros didáticos de Geografia, e novas propostas de práticas pedagógicas.

Entretanto, dois trabalhos propuseram reflexões relacionadas à Climatologia Geográfica e o ensino. Brito e Ferreira (2012), por exemplo, buscaram compreender como a Climatologia Geográfica foi, ao longo do tempo, sendo incorporada à educação básica, discutindo sobre as lacunas no processo de ensino-aprendizagem. Soares et al.(2012) apresentaram o resultado de um modelo de valorização da prática em Climatologia Geográfica no ambiente escolar, que considerou a relação empírica entre alunos e os instrumentos climatológicos, tratando também de princípios teóricos como fundamento associados a prática do trabalho de campo. Embora, não tenham tratado a Climatologia Geográfica como indica Sant'Anna Neto (2001, 2008), os autores demonstraram que o ensino ainda não incorporou a ideia de uma Climatologia que avançasse o ensino tradicional.

Verificou-se que embora existam variações nas temáticas desde a primeira edição do SBCG, não foram identificadas mudanças importantes do ponto de vista teórico, uma vez que duas questões continuam sendo as referências básicas para os estudos sobre ensino de Climatologia. A primeira questão referese a abordagem do conteúdo de Climatologia presentes nos livros didáticos de Geografia, procurando responder como está organizado o conhecimento sobre esse tema e indicar os erros; quais as metodologias para a aprendizagem do conhecimento, e se a aplicação de metodologias de intervenção pedagógica complementar ao livro didático contribuem efetivamente para o processo de ensino-aprendizagem do aluno. Já a segunda questão mais abordada são as práticas didáticas que utilizam a prática de campo e recursos diferenciados para o ensino.

Sendo assim, é possível afirmar que existe uma gama de trabalhos que tem se preocupado com a elaboração de novas metodologias e práticas pedagógicas com o intuito de melhoria do ensino-aprendizagem de Climatologia, em todos os níveis de escolaridade, mas principalmente, no Ensino Fundamental.

Fialho (2010) questiona porque somente depois de muito tempo, desde a primeira edição do SBCG, começou a existir maior preocupação com o tema. 0 autor elenca alguns fatores, a saber: a possibilidade de estar esse tema (ensino) em voga, de o aumento no número de trabalhos ser reflexo das exigências de produção científica por parte dos órgãos avaliadores das instituições universitárias e financiadores de pesquisas, e, ainda, de ser um problema, a distância entre o conhecimento acadêmico e o escolar, o que pode estar gerando uma maior preocupação por parte dos estudiosos, os quais estão procurando refletir sobre novas formas de se ensinar temáticas da Climatologia.

Outro fator pode estar relacionado ao descompasso entre as aulas de Geografia e o mundo em constante transformação. Apesar de os Parâmetros Curriculares Nacionais - PCN's (BRASIL, 1998) recomendarem que as escolas adotem uma abordagem em que o professor ensine uma Geografia para que os alunos possam realizar uma leitura da realidade de forma não fragmentada e contemplando os principais avanços dessa disciplina, o cenário atual de uma aula de Geografia, no Ensino Básico, não difere muito do que se via há algumas 
décadas. Como já foi mencionado, estudos nessa área tem apontado novos caminhos para um ensino mais contextualizado e mais agradável para os alunos, contudo, muitas vezes os professores não estão preparados para tais inovações ou mesmo não conseguem colocá-las em prática. As técnicas de ensino mais comuns são ainda aquelas voltadas para a memorização e a realização e exercícios mecânicos.

O que se tem visto é que o conhecimento acadêmico possui uma enorme desvinculação com o conhecimento escolar. Vários trabalhos mostraram que o aluno-professor que se depara com uma turma de $6^{\circ}$ ano do Ensino Fundamental possui muita dificuldade em transpor o conhecimento que ele adquiriu na faculdade para uma aula onde o processo cognitivo de memorização não seja o predominante. Isso, sem falar na forma estanque e desarticulada em que os conteúdos aparecem na maioria dos livros didáticos, como mostraram Nervis et al. (2012). No âmbito escolar, os Parâmetros Curriculares Nacionais PCN's (1998) destacam a necessidade da inserção de temas em Climatologia no Ensino Fundamental, sugerindo, inclusive, a utilização da percepção empírica sobre a sucessão dos tipos de tempo. Ocorre que, se o professor não lançar mão de práticas que utilizem todos os processos cognitivos, nem mesmo com a percepção empírica os alunos conseguirão compreender a primeiras noções de tempo e clima e nem estabelecer relações simples entre estas noções e a sociedade.

Acredita-se que a relação dinâmica que existe entre o fenômeno climático e as sociedades tem o papel de confrontar a ação do homem e a ação do clima como agente externo. E para que a Climatologia praticada por geógrafos/professores avance nesse sentido, faz-se necessário trazer para a vivência/realidade dos alunos uma forma de unir a prática das salas de aula com as experiências que o mundo globalizado impõe para a formação da cidadania. Só assim ter-se-á avançado sobre o paradigma do ritmo climático para, então, trabalhar-se com a noção de clima, de acordo com Sant'Anna Neto (2008):

à luz do processo de globalização e mundialização, assumindo os conceitos de apropriação da natureza por uma sociedade estabelecida em classes sociais (Santa'Anna Neto, 2008, p. 46).

Se os estudiosos da Climatologia que se dedicam ao seu ensino não valorizarem essa perspectiva, é possível que a Climatologia escolar continue a ser muito mais representada por meio dos conteúdos do quadro físico/natural que são incorporados ao ensino de Ciências, como já havia alertado Passos (2003).

\section{CONSIDERAÇÕES FINAIS}

Os resultados dessa investigação mostraram que, embora o número de pesquisas, em ensino de clima, apresentadas nas dez edições dos SBCG's, tenha aumentado ao longo do tempo (comprovando que as pesquisas acadêmicas têm mostrado esforços contínuos), esse tema carece de estudos, principalmente aqueles relacionados ao ensino de Climatologia sob a orientação da Geografia do Clima. Do número total de trabalhos apresentados sobre a temática, nas nove edições dos SBCG's, nenhum abordou a Geografia do Clima como base para o 
ensino, e poucos trataram da Climatologia Geográfica como aporte teórico para as pesquisas sobre ensino, e mesmo assim, de forma incompleta.

Isso mostra que estudos a respeito de como ensinar Climatologia, sob a real perspectiva da Geografia, necessitam ser desenvolvidos pelos geógrafos. Ainda há necessidade de estudos focalizados nas dificuldades existentes no processo de ensino-aprendizagem da Climatologia escolar que, na maioria das vezes, a caracteriza como um ensino tedioso e acompanhado por práticas de memorização dos conteúdos. Após o início do nosso interesse pelo tema, observou-se que existem alguns fatores que justificam o desânimo dos professores e dos alunos para ensinar/aprender Climatologia. Entre eles, os principais tem sido: a falta de habilitação dos professores em Licenciatura em Geografia, já que os professores do Ensino Fundamental I, especificamente, são formados em Pedagogia; utilização excessiva de aulas expositivas como metodologia de ensino; utilização exclusiva do livro didático como único recurso pedagógico; falta de formação continuada dos professores para melhorar as práticas de ensino.

É possível que muitas pesquisas nesse tema ainda não tenham sido divulgadas para a comunidade acadêmica por meio dos SBCG's, principalmente aquelas desenvolvidas no norte do país, mesmo como a última edição sendo realizada na cidade de Manaus/AM. Recomenda-se que mais pesquisas, com o intuito elaborar práticas pedagógicas sob o olhar da Geografia do Clima, sejam desenvolvidas e visem a aprendizagem efetiva, ou seja, aquela em que o aluno efetivamente aprenda o que foi ensinado.

\section{Agradecimentos}

Os autores agradecem ao professor João Afonso Zavattini, da Universidade Estadual Paulista - UNESP, campus de Rio Claro, por disponibilizar os cadernos de resumos dos $1^{\circ}$ e $2^{\circ}$ SBCG's.

\section{REFERÊNCIAS}

ALVES, R. E.; MARIANO, Z. F.; CABRAL, J. B. P. Uso de música no ensino de Geografia. In: IX SIMPÓSIO BRASILEIRO DE CLIMATOLOGIA GEOGRÁFICA, 9, 2010. Fortaleza. Anais... Fortaleza: UFC, 1 CD-ROM.

BRASIL. Ministério da Educação e Cultura. Secretaria de Ensino Superior. Parâmetros Curriculares Nacionais: terceiro e quarto ciclo do ensino fundamental: introdução. Brasília: MEC, 1998.

BRITO, M. C. de; FERREIRA, C. de C. M. Por uma Climatologia Geográfica escolar no cotidiano: estimulando reflexões e a criatividade dos educandos. Revista Geonorte, Edição Especial 2, V.1, N.5, p.218 - 231, 2012.

COMPIANI, M. Geociências no ensino fundamental e a formação de professores: o papel dos trabalhos de campo. Tese de livre docência. Departamento de Geociências Aplicadas ao Ensino, Universidade Estadual de Campinas, IG/UNICAMP, 2002.

COSTA, M. S. DA; BORGES, F. DA R.; SILVA, V. E. G. DA; BARBOSA, M. E. S. A Utilização de Novos Recursos Didáticos no Ensino de Climatologia. In: IX SIMPÓSIO BRASILEIRO DE CLIMATOLOGIA GEOGRÁFICA, 9, 2010. Fortaleza. Anais... Fortaleza: UFC, 1 CD-ROM. 
CRISCUOLO, C.; LOMBARDO M. A. MARTINS, J. S; SANTOS. M. F.; VILLA, E. A. Livro didático em Geografia: abordagem dos conceitos climatológicos. IN: SIMPÓSIO BRASILEIRO DE CLIMATOLOGIA GEOGRÁFICA, 3, 1998. Presidente Salvador, Anais... Salvador: Ufba, p. 59.

FERREIRA, J. C. e DANIEL, L. A. Conservação e uso da água e do solo - programa educativo "Brincando com a terra". IN: SIMPÓSIO BRASILEIRO DE CLIMATOLOGIA GEOGRÁFICA, 2, 1996. Presidente Prudente, Anais... Presidente Prudente: Unesp, p. 99.

FIALHO, E. S. Prática de ensino de Climatologia através da observação sensível. Agora. v. 13, p. 105-123, 2007. Disponível em http://online.unisc.br/seer/index.php/agora/article/view/112/71. Acesso em agosto de 2011.

FIALHO, E. S. A pesquisa climatológica realizada por geógrafos brasileiros. Revista Brasileira de Climatologia. Ano 6, v. 6, p. 193-212, 2010.

FIALHO, E. S.; AZEVEDO, T. R. Uma análise da produção climatológica, na ciência geográfica brasileira entre 1992 e 2004. In: SIMPÓSIO BRASILEIRO DE CLIMATOLOGIA GEOGRÁFICA, 7, 2006. Rondonópolis, Anais... Rondonópolis: UFMT, CD-ROM.

FREIRE, M. R. O clima no ensino de arquitetura: elaboração de maquetes para a observação de elementos climáticos. IN: SIMPÓSIO BRASILEIRO DE CLIMATOLOGIA GEOGRÁFICA, 3, 1998. Presidente Salvador, Anais... Salvador: Ufba, p. 60.

LIMA, M. das G. Climatologia: Reflexões Sobre seu Ensino no Curso De Graduação em Geografia. In: SIMPÓSIO BRASILEIRO DE CLIMATOLOGIA GEOGRÁFICA, 7, 2006. Rondonópolis, Anais... Rondonópolis: UFMT, CD-ROM.

MACHADO, D. V; FREIRE, R. G; SILVA, A. P. R. da; VIEIRA, J. C. R; FIALHO, E. S. MAPEAMENTO PLUVIAL: Uma Experiência Didática-Pedagógica para a Região Metropolitana do Rio de Janeiro. In SIMPÓSIO BRASILEIRO DE CLIMATOLOGIA GEOGRÁFICA, 6, 2004. Sergipe, Anais... Sergipe: UFSE, CD-ROM.

MAIA, D. C.; MAIA, A. C. N. A utilização dos ditos populares e da observação do tempo para a Climatologia Escolar no Ensino Fundamental II. In SIMPÓSIO BRASILEIRO DE CLIMATOLOGIA GEOGRÁFICA, 9, 2010. Fortaleza, Anais... Fortaleza: UFCE, CD-ROM.

MENDONÇA, F. A.; FERNANDES DE OLIVEIRA. A filmografia como recurso didático para o ensino de Climatologia. In: SIMPÓSIO BRASILEIRO DE CLIMATOLOGIA GEOGRÁFICA, 8, 2008. Alto Caparaó, Anais... Alto Caparaó: UFU, CD-ROM.

MISSIO, L. R; SARTORI, M. da G. B; ALMEIDA, A. P. O clima nos livros didáticos de geografia no Ensino Fundamental em Santa Maria/RS. In: SIMPÓSIO BRASILEIRO DE CLIMATOlOGIA GEOGRÁFICA, 5, 2002. Curitiba, Anais... Curitiba: UFPR, CD-ROM.

NERVIS, D. E.; SOUZA, MALU Í. A.; ALVES, A. O. S. Análise do conteúdo de Climatologia em livros didáticos de geografia do $5^{\circ}$ e $6^{\circ}$ ano do Ensino Fundamental. Revista Geonorte, Edição Especial 2, V.1, N.5, p.46-58, 2012.

PAULA, D. O.; de; STEINKE, E. T. Elaboração de material didático de climatologia em multimídia para o Ensino Fundamental. In: ENCUENTRO DE GEGRAFOS DA AMERICA LATINA, 12, 2009. Montevidéu, Anais... Montevidéu: UdeLar. 1 CD-ROM. 
PASSOS, W. S. A Geografia no Ensino Fundamental e Médio: Uma Análise Crítica. In: X SIMPÓSIO BRASILEIRO DE GEOGRAFIA FÍSICA APLICADA, 10, 2003. Rio de Janeiro. Anais... Rio de Janeiro: UFRJ. 1 CD-ROM.

PIMENTEL, A. B. de S.; COSTA, A. C. L. da. Recurso Didático Para Disciplina Meteorologia Ambiental: Construção em Interface com a Geografia. In: SIMPÓSIO BRASILEIRO DE CLIMATOlogia GEOGRÁFICA, 7, 2006. Rondonópolis, Anais... Rondonópolis: UFMT, CDROM.

RIBEIRO, A. G; ASSUNÇÃO, W. L; ARANTES, A. de O; MACEDO, D; FRANCO, J. B. S. A montagem do mini posto climatológico: uma experiência educacional. IN: SIMPÓSIO BRASILEIRO DE CLIMATOLOGIA GEOGRÁfICA, 2, 1996. Presidente Prudente, Anais... Presidente Prudente: Unesp, p. 99. (a)

RIBEIRO, A. G; MENDES, P. C.; COSTA, R. A; ASSUNÇÃO, W. L. a Climatologia nas escolas de $1^{\circ}$ grau de Uberlândia - MG. IN: SIMPÓSIO BRASILEIRO DE CLIMATOLOGIA GEOGRÁFICA, 2, 1996. Presidente Prudente, Anais... Presidente Prudente: Unesp, p. 100. (b)

SANT'ANNA NETO, J. L. Por uma Geografia do Clima: antecedentes históricos, paradigmas contemporâneos e uma nova razão para um novo conhecimento. Terra Livre, no 17, p. 49-62, 2001.

SANT'ANNA NETO, J. L. Da Climatologia Geográfica à Geografia do Clima: gênese, paradigmas e aplicações do clima como fenômeno geográfico. Anpege, São Paulo, v. $4,2008$.

SANT' ANNA NETO, J. L. Perspectivas e desafios da Climatologia Geográfica brasileira no Brasil. In: SIMPÓSIO BRASILEIRO DE CLIMATOLOGIA GEOGRÁFICA, 9, 2010. Dourados, Anais... Dourados: UFGD, 1 CD-ROM.

SANTOS, F. V. dos. Os jogos pedagógicos como proposta de ensino e aprendizagem de Climatologia. In: SIMPÓSIO BRASILEIRO DE CLIMATOLOGIA GEOGRÁFICA, 8, 2008. Alto Caparaó, Anais... Alto Caparaó: UFU, CD-ROM.

SIMPÓSIO BRASILEIRO DE CLIMATOLOGIA GEOGRÁfICA, 1., 1992, Rio Claro. Anais... Rio Claro: UNESP, 1992, 80p.

SIMPÓSIO BRASILEIRO DE CLIMATOLOGIA GEOGRÁFICA, 2., 1996, Presidente Prudente. Anais... Presidente Prudente: UNESP, 1996, 65p.

SIMPÓSIO BRASILEIRO DE CLIMATOLOGIA GEOGRÁFICA, 3., 1998, Salvador. Anais... Salvador: UFBA, 1998, 50p.

SIMPÓSIO BRASILEIRO DE CLIMATOLOGIA GEOGRÁFICA, 4., 2000, Rio de Janeiro. Anais... Rio de Janeiro: Climageo/Crea-RJ, 2000, 75p.

SIMPÓSIO BRASILEIRO DE CLIMATOLOGIA GEOGRÁFICA, 5., 2002, Curitiba. Anais... Curitiba: UFPR, 2002. CD-ROM.

SIMPÓSIO BRASILEIRO DE CLIMATOLOGIA GEOGRÁfICA, 6., 2004. Aracajú. Anais... Aracajú: UFSE , 2004, 190p.

SIMPÓSIO BRASILEIRO DE CLIMATOLOGIA GEOGRÁFICA, 7., 2006. Rondonópolis. Anais... Rondonópolis: UFMT, 2006, 257p. 
SIMPÓSIO BRASILEIRO DE CLIMATOLOGIA GEOGRÁFICA, 8., 2002, Alto do Caparaó. Anais... Minas Gerais: UFU, 2008. CD-ROM.

SOARES, L. P.; SILVA, A. A. G. da; FÉLIX, F. K. L.; ZANELLA, M. E. Práticas Educativas em Climatologia Geográfica. Revista Geonorte, Edição Especial 2, V.1, N.5, p.232 - 240, 2012.

SOUSA, R. R. DE; ASSUNÇÃO, H. F. da; SILVA, E. M. da. Uma Nova Visão de Climatologia Geográfica Para Professores do Ensino Fundamental e Médio dos Municípios de Portelândia e Mineiros-Go, a Partir da Utilização de Sucatas. In: SIMPÓSIO BRASILEIRO DE CLIMATOlogia GeOGRÁfICA, 6, 2004. Sergipe, Anais... Sergipe: UFSE, CD-ROM.

STEINKE, E. T., GOMES. K. F. Instrumentação para o ensino de temas em Climatologia com material multimídia. Didácticas Específicas, v. 5, p. 01-19, 2011.

STEINKE, V. A.; CARVALHO, A. C. A. As dimensões da formação de profissionais em Geografia no Brasil: reflexões introdutórias. In: SILVA, Eunice Isaias da; PIRES, Lucineide Mendes. (Org.). Desafios da didática de Geografia. $1^{a}$. ed.Goiania: PUC, 2013, v. , p. 69-85.

STRAFORINI, Rafael. A totalidade mundo nas primeiras séries do Ensino Fundamental: um desafio a ser enfrentado. Terra livre, São Paulo, 2002.

TAVEIRA, I. A. P.; STEINKE, E. T. Identificação de temas em Climatologia de difícil transposição didática no Ensino Fundamental. Anais do 90 Congresso de Iniciação Científica do DF e $18^{\circ}$ Congresso de Iniciação Científica da UnB. Brasília: UnB, 2014. 1 CD ROM.

VILLA, E. A. e TAVARES, A. C. Análise dos conceitos climatológicos ministrados nas disciplinas de Geografia e Ciências no ensino público de $1^{\circ}$ grau no município de Leme - SP.

ZAVATTINI, J. A. Desenvolvimento e perspectivas da climatologia geográfica no Brasil: $O$ enfoque dinâmico, a noção de ritmo climático e das mudanças climáticas. In: SANT'ANNA NETO, J. L.; ZAVATINI, J. A. (org.).: Variabilidade e mudanças climáticas: Implicações ambientais e socioeconômicas. Maringá: Eduem, p. 225-249, 2000.

ZAVATTINI, J. A.; FRATIANNI, S.; BIANCOTTI, A. A Climatologia Geográfica e o estudo de clima na Itália: Comparação Com o Brasil e Aplicações Práticas (Neve, Turismo,"Terroir"). In: SIMPÓSIO BRASILEIRO DE CLIMATOLOGIA GEOGRÁFICA, 7, 2006. Rondonópolis, Anais... Rondonópolis: UFMT, CD-ROM. 